\title{
Is there a BMI Threshold Value Associated with a Lower Physical Capacity in Well-Functioning Older Adults? The Quebec Longitudinal Study
}

\author{
Danielle R. Bouchard ${ }^{*, 1,2}$, Isabelle J. Dionne ${ }^{1,2}$, Hélène Payette ${ }^{1,3}$ and Martin Brochu ${ }^{1,2}$ \\ ${ }^{1}$ Research Centre on Aging, Health and Social Services Centre- Sherbrooke University Institute of Geriatrics, ${ }^{2}$ Faculty \\ of Physical Education and Sports and ${ }^{3}$ Faculty of Medicine and Health Sciences, University of Sherbrooke, Sherbrooke, \\ Quebec, Canada
}

\begin{abstract}
Objective: Identify a body mass index (BMI) threshold above which physical capacity would be significantly affected. Methods: This study included 904 physically independent older individuals aged between 67 and 84 years old. Measures were: BMI, physical capacity score (PCS) computed according to five lower extremity physical tests, sum of reported chronic conditions and physical activity level. Results: When subjects were divided in 10 BMI groups, no clear threshold was identified in men since the PCS was only significantly decreased in the heaviest group, which correspond to a BMI of $>34.5 \mathrm{~kg} / \mathrm{m}^{2}$. In women, a BMI of $30.5 \mathrm{~kg} / \mathrm{m}^{2}$ was identified as the threshold above which the PCS was significantly decreased compared with the reference group. Discussion: Although no clear BMI threshold was identify in older men, a BMI of $30.5 \mathrm{~kg} / \mathrm{m}^{2}$ in women was associated with a significantly lower physical capacity.
\end{abstract}

Keywords: Aging, body composition, BMI critical value, mobility.

\section{INTRODUCTION}

Statistics show that the Canadian population is aging [1]. Parallel to this demographic change, cross-sectional and longitudinal studies concluded that aging is associated with significant alterations in body composition, with decreases in muscle mass and increases in fat mass [2,3]. These body composition changes, associated with a more sedentary lifestyle and decreases in energy expenditure [4], contribute to the increase of obesity prevalence in older individuals. For example, between 1978 and 2004, the prevalence of obesity increased from $11 \%$ to $24 \%$ in the population aged $\geq 75$ years old [5].

A high body mass index (BMI) has been negatively associated with lower physical capacity $[6,7]$, which in turn may increase the risk of frailty and disability. For example, Baumgartner et al. [8] showed that $15.1 \%$ of older obese individuals reported a loss of physical capacity within 8 years. A BMI over $30 \mathrm{~kg} / \mathrm{m}^{2}$ has been reported to be associated with a greater risk of metabolic complications [9], but no specific threshold has been proposed for physical limitations in well-functioning older despite the fact that BMI has been frequently used to assess the relationship between body composition and physical capacity [10-15]. In fact, only a few studies have proposed a BMI above which lower physical capacity may be observed $[11,16]$. Results

\footnotetext{
*Address correspondence to this author at the Centre de recherche sur le vieillissement, Institut universitaire de gériatrie de Sherbrooke, 1036, rue Belvédère Sud, Sherbrooke (Québec), J1H 4C4, Canada; Tel: (819) 8211150 \#45303/45326; Fax: (819) 829-7141;

E-mail: Danielle.Bouchard@USherbrooke.ca
}

are inconsistent and may be caused by the variety of tests and/or questionnaires used to evaluate physical capacity [7, 17, 18]. Consequently, proposed BMI thresholds vary between 25 and $40 \mathrm{~kg} / \mathrm{m}^{2}$ depending on the methodology used and the population studied [11, 16]. It would be important to identify a specific threshold over which BMI is significantly associated with low physical capacity. Therefore, it could be possible to better identify who may be at greater risks of presenting lower physical capacity and prevent long-term associated problems such as early institutionalization [19], longer duration of hospitalization [20] and important health cost [21].

To our knowledge, only one study used objective tests to evaluate physical capacity in older individuals in order to identify a BMI threshold over which physical performance would be significantly lower [22]. This study, conducted in men and women aged between 55 and 79 years [22], showed that a BMI $>30 \mathrm{~kg} / \mathrm{m}^{2}$ was associated with a significantly slower walking speed in men and women. However, walking ability might not represent the general physical capacity of older individuals. Thus, other objective measures of physical capacity related to daily activities may help to better identify a threshold above which BMI is associated with lower physical capacity.

The study of well-functioning older adults in the present research project was in part motivated by the fact that Gill et al. [23] showed that approximately $10 \%$ of non-disabled community-dwelling adults aged over 75 years lose independence in basic activities each year. Thus, early identification of well-functioning individuals displaying low physical capacity might help to prevent or delay loss of independence. 
Therefore, we attempted to overcome limitations of the current scientific literature by studying a large cohort of older men and women using objective and validated measures of physical capacity. These results are of great interest for the population aged over 65 years considering the fact that $30 \%$ are considered as obese [5], and $40 \%$ report at least one limitation, mobility being the most reported one [24].

\section{MATERIALS AND METHODOLOGY}

\section{Subjects}

The NuAge study (Nutrition as a determinant of successful aging study) is a 5-year observational study of 1793 community-dwelling men and women aged 67-84 years in good general physical and mental health and functionally independent at recruitment in 2003. The study sample was drawn from a random sample stratified by age and sex obtained from the Quebec Medicare database in Laval, Montreal and Sherbrooke areas. Participants were recruited in each age strata are as follow: $70 \pm 2$ years: 337 W, 329 M; $75 \pm 2$ years: 305 W, 289 M; $80 \pm 2$ years: 298 W, 235 M. Participants were tested annually using a series of nutritional, functional, medical, biological and social measurements. Data were collected by trained research dieticians and nurses using computer-assisted personal interview methodology following rigorous standardized procedures. For the present study, analyses were performed using baseline data obtained from the 464 women and 438 men living in the Sherbrooke area.

Selection of subjects was carried out in 2 phases: a telephone survey and clinical examination. Inclusion criteria were: French or English speaking, willing to commit for a 5 year-period, able to walk without assistance (cane acceptable), free of disabilities in activities of daily living, no cognitive impairment [Mini Mental State Exam > 79], able to walk 300 meters (one block), able to climb 10 stairs (one floor) without rest, and able to sign an informed consent form. People suffering from class II heart failure, chronic obstructive pulmonary disease requiring home oxygen therapy or oral steroids, inflammatory digestive disease, cancer treated by radiation therapy, chemotherapy or cancer surgery in the 5 years prior to enrolment (with the exception of basal skin cell carcinoma) were excluded. All participants signed an informed consent form approved by the Ethics committees of the Institut Universitaire de Gériatrie de Montréal and the Sherbrooke Geriatric University Institute.

\section{Anthropometric Indicators}

Body weight and standing height were measured as described by Lohman et al. [25]. BMI was also calculated [body weight $(\mathrm{kg}) /$ height $\left(\mathrm{m}^{2}\right)$ ]. Since BMI categories proposed by the WHO [26] may not be optimal for body composition assessment in the elderly population [27-30], men and women were categorized using $1.5 \mathrm{~kg} / \mathrm{m}^{2}$ BMI intervals in order to obtain 10 groups. This strategy allowed us to have a minimum of 23 subjects in each group. The reference group was arbitrary chosen by identifying the closest BMI deciles corresponding to the central value of the "normal" BMI category, as proposed by the World Health
Organization (18.50 to $24.99 \mathrm{~kg} / \mathrm{m}^{2}$ ) [31]. This corresponded to the second group in our cohort of older women (21.50$22.99 \mathrm{~kg} / \mathrm{m}^{2}$ ) and men $\left(22.50-23.99 \mathrm{~kg} / \mathrm{m}^{2}\right)$.

\section{Physical Capacity Score (PCS)}

The PCS was determined using a set of five validated physical tests: timed up and go [32], chair stand, walking speed at normal and fastest pace [33], and one leg stand [34]. Two attempts were made for each test. The maximum score was used for analyses, except for the one leg stand where the mean value of both legs was used. Each test was then attributed a score of 1 to 4 using quartiles of performance (ex: $4^{\text {th }}$ quartile $=4$ points and $1^{\text {st }}$ quartile $=1$ point $)$, as previously done [35]. A score of 0 was attributed to those who were unable to perform a test. Quartile scores by gender were then added to produce the PCS for each subject (possible score ranging between 0 and 20). The main advantage of doing the analysis on the PCS is that it gives a global picture of subjects' lower limbs performance by taking into account several tasks related to daily activities, as previously suggested [33].

\section{Physical Activity Level}

Physical activity level was assessed using the Physical Activity Scale for the Elderly questionnaire (PASE) [36]. Subjects reported leisure time, household and work-related activities during the past week. Daily activities were first scored according to the intensity and duration of reported activities and then added to produce a physical activity score (possible range of scores between 0 - 793).

\section{Sum of Reported Chronic Conditions}

18 different chronic conditions plus a miscellaneous category were reported by each participant using a modified version of the Older American Resources and Services questionnaire [37]. Subjects were asked to answer « yes (1)» or « no (0)» if they were presently suffering from chronic conditions as listed. The chronic conditions known to be related to obesity such as arthritis [38], edema [39], asthma [40], high blood pressure [41], heart diseases [42], thyroid problem [43] and osteoporosis [44] were used in the present analysis. The sum of chronic conditions was recorded by adding the number of positive answers giving a maximum sum of 7 .

\section{Statistical Analyses}

Since the PCS and his residuals were normally distributed in men and women, parametric analyses were used. Independent T-tests were performed to compare men and women for descriptive characteristics. Pearson's correlations were used to quantify the relationship between BMI and the PCS. ANOVA analyses were used to compare BMI groups, while ANCOVA analyses were used to adjust means for the sum of chronic conditions and age. When these procedures revealed a significant group effect, the Dunnet post-hoc test was used for posteriori group comparisons, with the $2^{\text {nd }}$ BMI category (21.50 to 22.99 $\mathrm{kg} / \mathrm{m}^{2}$ in women and 22.50 to $23.99 \mathrm{~kg} / \mathrm{m}^{2}$ in men) as the group of reference. This approach allowed us to identify a 
Table 1. Characteristics of Men and Women

\begin{tabular}{|c|c|c|c|}
\hline Variables & Men $(\mathbf{N}=\mathbf{4 3 9})$ & Women $(\mathbf{N}=\mathbf{4 6 5})$ & P Value \\
\hline \hline Age $($ years $)$ & $73.8 \pm 4.2$ & $74.1 \pm 4.1$ & 0.33 \\
\hline BMI $\left(\mathrm{kg} / \mathrm{m}^{2}\right)$ & $28.1 \pm 4.3$ & $27.7 \pm 4.8$ & 0.19 \\
\hline Weight $(\mathrm{kg})$ & $78.7 \pm 13.5$ & $65.9 \pm 11.7$ & $<0.01$ \\
\hline Pum of reported chronic conditions $(0-7)$ & $120.5 \pm 59.2$ & $93.0 \pm 45.4$ & $<0.01$ \\
\hline
\end{tabular}

Results are presented as mean \pm standard deviation. $\mathrm{BMI}=$ Body mass index Unpaired T-tests were used to identify a difference between men and women

BMI threshold above which physical capacity was decreased. Finally, an unpaired T-test was used to compare subjects with a BMI "above" and "below" the identified threshold in order to confirm it. Significance was accepted at $P<0.05$. Analyses were performed using SPSS 12.0 program (Chicago, IL) and Stat View 5.01 (SAS Institute Inc, Cary, NC, USA).

\section{RESULTS}

\section{Cohort's Characteristics}

As shown in Table 1, age and BMI were similar in men and women. Men had a higher body weight and physical activity level $(\mathrm{P}<0.01)$, while women had, in average, significantly more reported chronic conditions $(\mathrm{P}<0.01)$. Finally, men had better scores for each physical capacity test performed (all $\mathrm{P}<0.01$ ).

\section{Relationships between BMI and PCS}

Results from Pearson's correlation analyses show that even if significant, BMI was weakly correlated with the PCS in men $(\mathrm{r}=-0.20 ; \mathrm{P}<0.001)$ and women $(\mathrm{r}=-0.23 ; \mathrm{P}<$ $0.001)$.

\section{Groups Comparisons}

Characteristics of BMI groups are presented in Table 2. In men, groups were similar for age and physical activity level, while different sum of reported chronic conditions $(\mathrm{P}<$ $0.01)$. In women, groups were similar for physical activity level and the sum of reported chronic conditions, whereas they were different for age, with a significant difference between the $9^{\text {th }}$ group and the group of reference $(\mathrm{P}<0.05)$. In men, post-hoc analyses have shown that only the sum of reported chronic conditions was different for some groups compared to the reference group $(\mathrm{P}<0.05)$.

Results for the PCS for each BMI group are presented in Fig. (1). In men, groups 1 and 10 were the only ones significantly different from the reference group $[\mathrm{P}<0.05$; (Fig. 1a)]. In women, the PCS was significantly lower for those with a BMI $>30.5 \mathrm{~kg} / \mathrm{m}^{2}$ (groups 8 to 10 ) compared to the reference group $[\mathrm{P}<0.05$; (Fig. 1b)].

As a complementary analysis, an independent T-test was performed to compare women above and below the BMI threshold of $>30.5 \mathrm{~kg} / \mathrm{m}^{2}$ in order to confirm the threshold.
As anticipated, women above the proposed BMI threshold had a significantly lower PCS compared to the other group (12.7 \pm 4.3 vs. $10.3 \pm 4.3 ; \mathrm{P}=0.002)$.

\section{DISCUSSION}

Our results show that BMI was weakly but significantly correlated with the PCS in our sample of well-functioning older men and women. In women, a BMI $>30.5 \mathrm{~kg} / \mathrm{m}^{2}$ was associated with a significantly lower physical capacity. The mean difference between the control group and the proposed BMI threshold correspond to an $8 \%$ lower PCS. Similarly to our results, others reported that older women with a BMI $\geq 30 \mathrm{~kg} / \mathrm{m}^{2}$ had an increased risk of functional limitations $[11,45,46]$. No clear threshold was identified in men since the PCS was significantly decreased only in the heaviest group, which correspond to a BMI of $>34.5 \mathrm{~kg} / \mathrm{m}^{2}$. The mean difference between the control group and the heaviest BMI group correspond to a $14 \%$ lower PCS. It is important to note that, compared to the other groups, subjects in the $10^{\text {th }}$ group were very heterogeneous in term of body composition, with BMIs ranging between 34.5 and 43.9 $\mathrm{kg} / \mathrm{m}^{2}$. Taking into account this limitation, our results are in agreement with those of Davidson et al. [11] and Jensen et al. [6] who also reported that a BMI threshold of $>35 \mathrm{~kg} / \mathrm{m}^{2}$ was associated with lower physical capacity. Taken together, our results could be helpful to identify those that may be at greater risk of having lower physical capacity. Consequently, longitudinal studies with similar objective measures will be needed to identify if the difference is clinically important. Our observations are also of great interest since studies showed that physical incapacity is associated with an increased risk of falling [22], loss of independence [23], early institutionalization [24] and longer hospitalization [25].

Several explanations have been proposed to describe the relationship between body composition and physical capacity. First, Walford et al. [47] suggested that excessive body weight contributes to inflammation of joints, making ambulating painful and difficult. Others showed that obesity increases the risk and severity of osteoarthritis [48], which may negatively affect physical activity level [49]. Second, a sedentary lifestyle favors weight gain and losses in muscle mass and strength, both increasing the risk of having lower physical capacity [50]. Finally, Baumgarner et al. [8] suggested that elderly displaying low level of muscle mass and high levels of body fat, known as sarcopenic-obesity, 


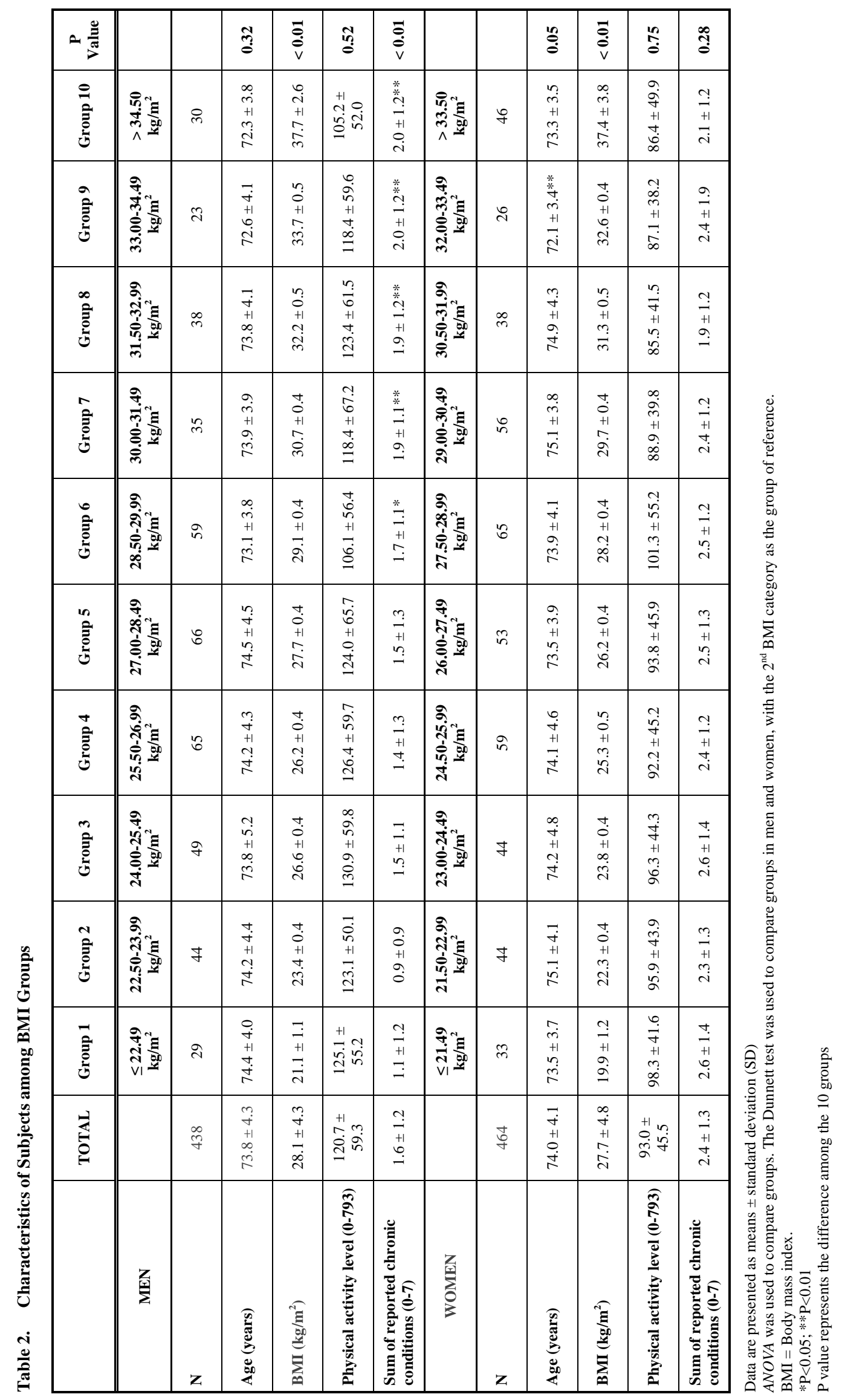




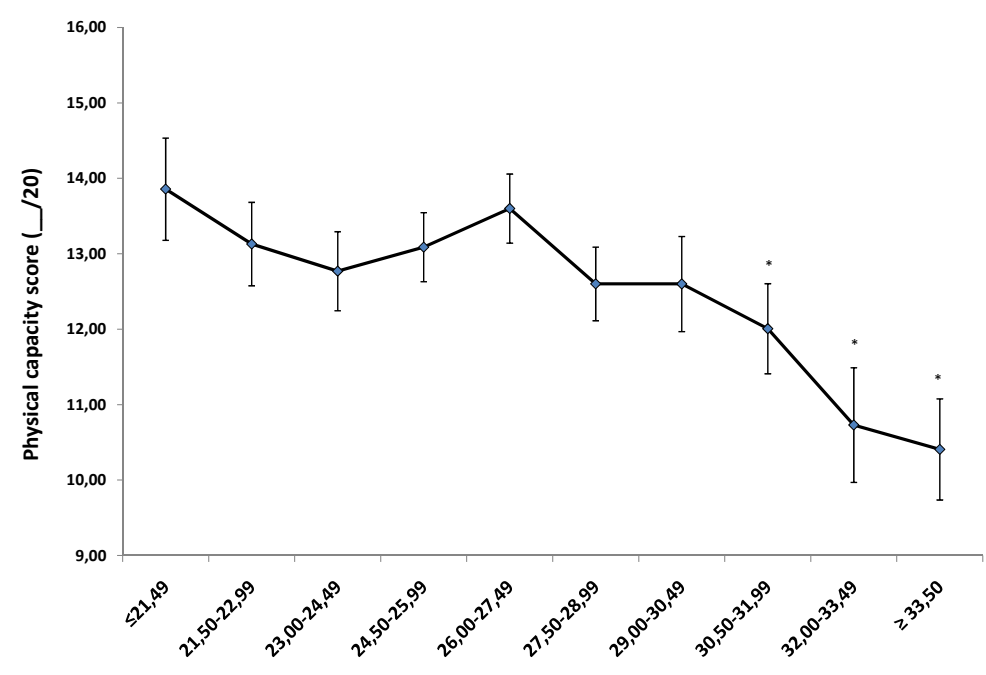

BMI group

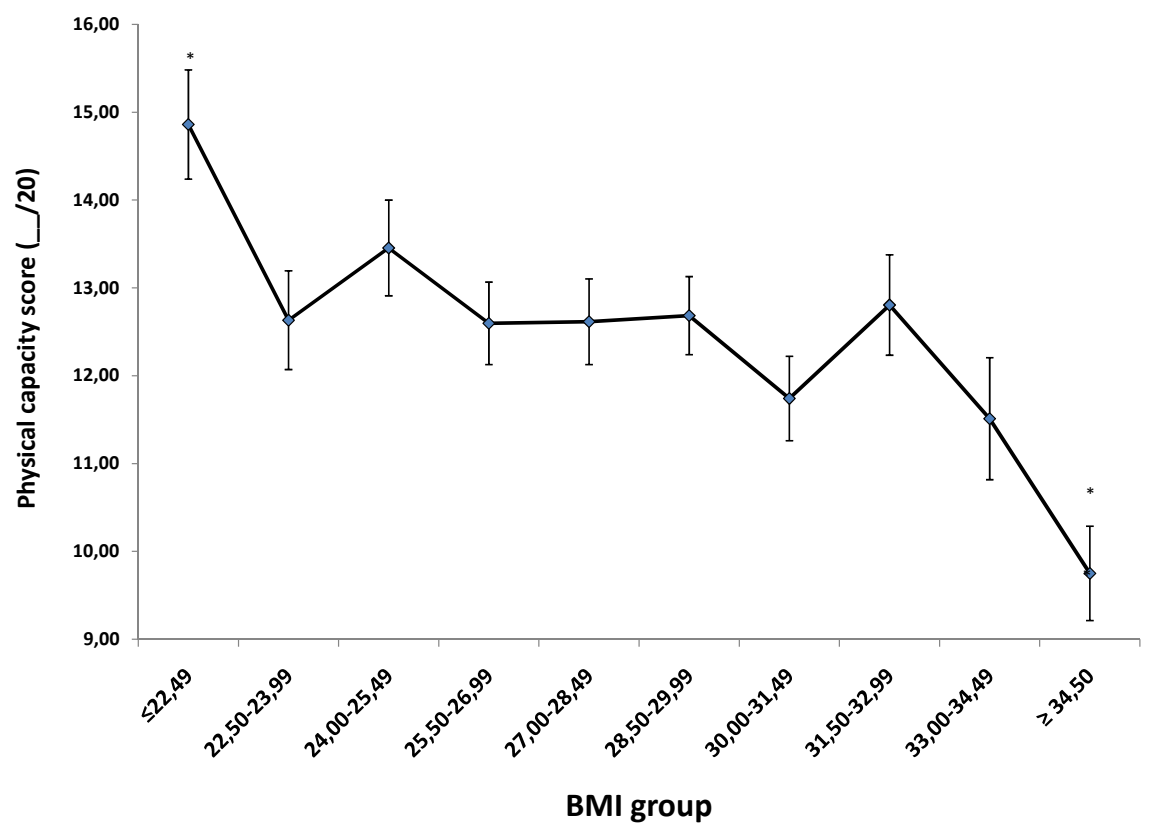

Fig. (1). Average physical capacity score in men (Fig. 1a) and women (Fig. 1b) by BMI deciles.

Data are presented as means \pm standard error (SE).

ANCOVA (adjusted for the sum of chronic conditions, physical activity level and age) were used to compare groups. The Dunnett test was used for posteriori comparisons, with the $2^{\text {nd }}$ BMI category as the group of reference.

$* \mathrm{P}<0.05$; significantly different from the reference group.

may experiment further physical capacity problems compared to those with a normal body weight. However, this concept needs to be further investigated since Davison et al. [11] concluded that sarcopenic-obesity was not associated with lower self-reported limitations.

Taken together, discrepancies between our results and other studies regarding BMI thresholds [7, 16, 17, 51] can partly be explained by BMI categorization or methods used to measure physical capacity (questionnaires vs. physical capacity tests). As a matter of fact, most of BMI thresholds proposed until now in order to identify individuals at risk of poor physical capacity were based on self-reported questionnaires $[11,45,46,52-54]$. Despite a significant relationship between questionnaires and physical capacity tests, correlations are generally less than $0.6[55,56]$. It has also been shown that objective physical capacity tests are less influenced by cultural, language and education levels than self-reported questionnaires [57].

The difference regarding BMI thresholds in women and men in the present study is not surprising considering gender effects previously reported in the literature. For example, Friedmann et al. [58] reported a lower physical capacity in men with a BMI > $40 \mathrm{~kg} / \mathrm{m}^{2}$ and women with a BMI > 35 $\mathrm{kg} / \mathrm{m}^{2}$, while Davison et al. [11] identified thresholds of 35 $\mathrm{kg} / \mathrm{m}^{2}$ and $30 \mathrm{~kg} / \mathrm{m}^{2}$ in men and women, respectively. We may thus hypothesize that differences reported between men 
and women in the present study are likely caused by differences in body composition and body fat distribution $[59,60]$. For example, Spyropoulos et al. [61] proposed that a gynoid profile (commonly seen in women) may affect the mechanical aspect of walking to a greater extent by slowing down walking speed because of upper leg friction.

Contrary to other studies, we did not identify a clear BMI threshold over which men would display a lower physical capacity. For example, Jensen et al. [6] proposed a BMI of $35 \mathrm{~kg} / \mathrm{m}^{2}$, while Peeters et al. [54] observed that men with a BMI above $30 \mathrm{~kg} / \mathrm{m}^{2}$ were twice as likely to report limitations later in life than those with a BMI between 25 and $29.9 \mathrm{~kg} / \mathrm{m}^{2}$. It is also likely that discrepancies between our results and those from others may be related to the physical effort needed to perform various physical tests. Indeed, the tests used in our study might not have been challenging enough for well-functioning older men.

Some limitations of the present study need to be addressed. First, the cross-sectional design precludes conclusions regarding cause and effect. Second, the use of BMI as an adiposity measure may be a limit in older individuals. Actually, BMI is correlated with fat mass in middle age adults $[62,63]$, however its use to predict fatness and to identify obese individuals is limited in older individuals [64-66]. Nevertheless, Jankowski et al. [67] recently reported that BMI was nearly as good as fat mass measured by Dual energy X- ray to predict physical function. Third, the selection of community-living older individuals may limit the potential for generalization of our results to institutionalized, homebound and frail older people. In fact, the cohort in the present study could be characterized as "physically capable" based on the walking speed threshold of $0.8 \mathrm{~m} / \mathrm{sec}$ proposed by Lauretani et al. [68]. Only $5.4 \%$ of our subjects had an average walking speed at normal pace lower than this threshold. It is important to note that other walking speed thresholds have also been proposed. For example, Langlois et al. [69] recommended a threshold of $1.22 \mathrm{~m} / \mathrm{sec}$ based on the ability to cross the street in the time typically allotted at signalized intersections. Based on this value, $27.4 \%$ of our cohort would be categorized as having physical capacity problems (walking speed $>1.22 \mathrm{~m} / \mathrm{sec}$ ). Consequently, the use of different cut-offs may have important impacts on the proportion of subjects that could be considered as having physical incapacities.

Despite limitations reported, the present study is strengthened by several factors. First, we use various validated and objective measures of physical capacity in a large and well-characterized cohort of men and women aged 68 to 82 years. This approach allowed us to compute and use the PCS for analyses. This aspect is very important since it has the advantage of giving an overall measure of subjects' performances by taking into account several tasks related to daily activities compared to the use of each test separately, as previously proposed [33]. Second, the use of validated and objective measures of physical capacity was critical since individuals displaying a lower physical capacity may adapt their environment as well as their daily life activities to their capabilities.

In conclusion, BMI was weakly but significantly associated with the PCS in both men and women. Although no clear threshold was identify in older men, a BMI of 30.5 $\mathrm{kg} / \mathrm{m}^{2}$ in women and $34.5 \mathrm{~kg} / \mathrm{m}^{2}$ in men were associated with a significantly lower physical capacity. Longitudinal studies using objective methods to measure physical capacity are needed to quantify the long-term potential impact of high BMI on physical capacity in older men and women.

\section{ACKNOWLEDGEMENTS}

This study was supported by the Canadian Institutes of Health Research (CIHR) and the Réseau québécois de recherche sur le vieillissement $(R Q R V)$. Isabelle J. Dionne and Danielle R. Bouchard were supported by the CIHR. Finally, the authors would like to thank Lise Trottier and Rokhaya N'Deye Gueye for statistical assistance.

\section{REFERENCES}

[1] Statistics Canada. Canada's aging population. Product \# H39-608 2002.

[2] Lakatta EG, Levy D. Arterial and cardiac aging: major shareholders in cardiovascular disease enterprises: Part I: aging arteries: a "set up" for vascular disease. Circulation 2003; 107(1): $139-46$.

[3] Spirduso WW, Francis KL, MacRae PG. Physical dimnensions of aging. $2^{\text {nd }}$ ed., Champaign IL: Human Kinetics 2005; p.384.

[4] Zamboni M, Mazzali G, Fantin F, et al. Sarcopenic obesity: A new category of obesity in the elderly. Nutr Metab Cardiovasc Dis 2008; 18(5): 388-95.

[5] Tjepkema M, Shields M. Adult obesity in Canada: Measured height and weight. Statistics Canada 2005.

[6] Jensen GL, Friedmann JM. Obesity is associated with functional decline in community-dwelling rural older persons. J Am Geriatr Soc 2002; 50(5): 918-23.

[7] Kaplan LM. Body weight regulation and obesity. J Gastrointest Surg 2003; 7(4): 443-51.

[8] Baumgartner RN, Wayne SJ, Waters DL, et al. Sarcopenic obesity predicts instrumental activities of daily living disability in the elderly. Obes Res 2004; 12(12): 1995-2004.

[9] Evans W. Functional and metabolic consequences of sarcopenia. J Nutr 1997; 127(5 Suppl): 998S-1003S.

[10] Apovian CM, Frey CM, Wood GC, et al. Body mass index and physical function in older women. Obes Res 2002; 10(8): 740-7.

[11] Davison KK, Ford ES, Cogswell ME, et al. Percentage of body fat and body mass index are associated with mobility limitations in people aged 70 and older from NHANES III. J Am Geriatr Soc 2002; 50(11): 1802-9.

[12] Elia M. Obesity in the elderly. Obes Res 2001; 9 (Suppl 4): 244S248S.

[13] Hue O, Simoneau M, Marcotte J, et al. Body weight is a strong predictor of postural stability. Gait Posture 2007; 26(1): 32-8.

[14] Sharts-Hopko NC, Sullivan MP. Obesity as a confounding health factor among women with mobility impairment. J Am Acad Nurse Pract 2003; 15(10): 438-43.

[15] Sulander T, Martelin T, Rahkonen O, et al. Associations of functional ability with health-related behavior and body mass index among the elderly. Arch Gerontol Geriatr 2005; 40(2): 185-99.

[16] Larrieu S, Peres K, Letenneur L, et al. Relationship between body mass index and different domains of disability in older persons: the 3C study. Int J Obes Relat Metab Disord 2004; 28(12): 1555-60.

[17] Blaum CS, Xue QL, Michelon E, et al. The association between obesity and the frailty syndrome in older women: the Women's Health and Aging Studies. J Am Geriatr Soc 2005; 53(6): 927-34.

[18] Jenkins KR. Obesity's effects on the onset of functional impairment among older adults. Gerontologist 2004; 44(2): 206-16.

[19] Guralnik JM, Simonsick EM, Ferrucci L, et al. A short physical performance battery assessing lower extremity function: association with self-reported disability and prediction of mortality and nursing home admission. J Gerontol 1994; 49(2): M85-94. 
[20] Penninx BW, Ferrucci L, Leveille SG, et al. Lower extremity performance in nondisabled older persons as a predictor of subsequent hospitalization. J Gerontol A Biol Sci Med Sci 2000; 55(11): M691-7.

[21] Ostir GV, Carlson JE, Black SA, et al. Disability in older adults. 1: Prevalence, causes, and consequences. Behav Med 1999; 24(4): 147-56.

[22] Yamakawa K, Tsai CK, Haig AJ, et al. Relationship between ambulation and obesity in older persons with and without low back pain. Int J Obes Relat Metab Disord 2004; 28(1): 137-43.

[23] Gill TM, Williams CS, Tinetti ME. Assessing risk for the onset of functional dependence among older adults: the role of physical performance. J Am Geriatr Soc 1995; 43(6): 603-9.

[24] Statistique Canada. Disability in Canada: A 2001 Profile N 89-577XIF 2001.

[25] Lohman TG, Roche AF. Anthropometric Standardization Reference Manual. In: Martorell R, Ed. Human Kinetics 1988; p. 184.

[26] WHO. Consultation on Obesity. Obesity Preventing and Managing the Global Epidemic. WHO Technical Report Series 894; Geneva, Switzerland 2000.

[27] Allison DB, Gallagher D, Heo M, et al. Body mass index and allcause mortality among people age 70 and over: the Longitudinal Study of Aging. Int J Obes Relat Metab Disord 1997; 21(6): 42431.

[28] Dey DK, Rothenberg E, Sundh V, et al. Body mass index, weight change and mortality in the elderly. A 15 y longitudinal population study of 70 y olds. Eur J Clin Nutr 2001; 55(6): 482-92.

[29] Engeland A, Bjorge T, Selmer RM, et al. Height and body mass index in relation to total mortality. Epidemiology 2003; 14(3): 2939.

[30] Stevens J, Plankey MW, Williamson DF, et al. The body mass index-mortality relationship in white and African American women. Obes Res 1998; 6(4): 268-77.

[31] WHO. Feedback on WHO/FAO global report on diet, nutrition and non-communicable diseases. Public Health Nutr 2003; 6(5): 425.

[32] Podsiadlo D, Richardson S. The timed "Up \& Go": a test of basic functional mobility for frail elderly persons. J Am Geriatr Soc 1991; 39(2): 142-8.

[33] Guralnik JM, Seeman TE, Tinetti ME, et al. Validation and use of performance measures of functioning in a non-disabled older population: MacArthur studies of successful aging. Aging (Milano) 1994; 6(6): 410-9.

[34] Lin MR, Hwang HF, Hu MH, et al. Psychometric comparisons of the timed up and go, one-leg stand, functional reach, and Tinetti balance measures in community-dwelling older people. J Am Geriatr Soc 2004; 52(8): 1343-8.

[35] Guralnik JM, Ferrucci L, Simonsick EM, et al. Lower-extremity function in persons over the age of 70 years as a predictor of subsequent disability. N Engl J Med 1995; 332(9): 556-61.

[36] Washburn RA, Smith KW, Jette AM, et al. The Physical Activity Scale for the Elderly (PASE): development and evaluation. J Clin Epidemiol 1993; 46(2): 153-62.

[37] Fillenbaum GG, Smyer MA. The development, validity, and reliability of the OARS multidimensional functional assessment questionnaire. J Gerontol 1981; 36(4): 428-34.

[38] Gross AF, Fickert S, Gunther KP. Obesity and arthritis. Orthopade 2005; 34(7): 638-44

[39] Blankfield RP, Hudgel DW, Tapolyai AA, et al. Bilateral leg edema, obesity, pulmonary hypertension, and obstructive sleep apnea. Arch Intern Med 2000; 160(15): 2357-62.

[40] Mosen DM, Schatz M, Magid DJ, et al. The relationship between obesity and asthma severity and control in adults. J Allergy Clin Immunol 2008; 122(3): 507-11.

[41] El-Atat F, Aneja A, McFarlane S, et al. Obesity and hypertension. Endocrinol Metab Clin North Am 2003; 32(4): 823-54.

[42] Bray GA. Medical consequences of obesity. J Clin Endocrinol Metab 2004; 89(6): 2583-9.

[43] Verma A, Jayaraman M, Kumar HK, et al. Hypothyroidism and obesity. Cause or effect? Saudi Med J 2008; 29(8): 1135-8.
[44] Zhao LJ, Jiang H, Papasian CJ, et al. Correlation of obesity and osteoporosis: effect of fat mass on the determination of osteoporosis. J Bone Miner Res 2008; 23(1): 17-29.

[45] Cesari M, Onder G, Russo A, et al. Comorbidity and physical function: results from the aging and longevity study in the Sirente geographic area (ilSIRENTE study). Gerontology 2006; 52(1): 2432 .

[46] Zoico E, Di Francesco V, Guralnik JM, et al. Physical disability and muscular strength in relation to obesity and different body composition indexes in a sample of healthy elderly women. Int $\mathbf{J}$ Obes Relat Metab Disord 2004; 28(2): 234-41.

[47] Walford RL, Harris SB, Weindruch R. Dietary restriction and aging: historical phases, mechanisms and current directions. J Nutr 1987; 117(10): 1650-4.

[48] Coggon D, Reading I, Croft P, et al. Knee osteoarthritis and obesity. Int J Obes Relat Metab Disord 2001; 25(5): 622-7.

[49] Andersen RE. Obesity: Etiology, Assessment, Treatment and Prevention. Champlain IL: Human Kinetics 2003.

[50] Himes CL. Obesity, disease, and functional limitation in later life. Demography 2000; 37(1): 73-82.

[51] He XZ, Baker DW. Body mass index, physical activity, and the risk of decline in overall health and physical functioning in late middle age. Am J Public Health 2004; 94(9): 1567-73.

[52] Ferraro KF, Booth TL. Age, body mass index, and functional illness. J Gerontol B Psychol Sci Soc Sci 1999; 54(6): S339-48.

[53] Lebrun CE, van der Schouw YT, de Jong FH, et al. Fat mass rather than muscle strength is the major determinant of physical function and disability in postmenopausal women younger than 75 years of age. Menopause 2006; 13(3): 474-81.

[54] Peeters A, Bonneux L, Nusselder WJ, et al. Adult obesity and the burden of disability throughout life. Obes Res 2004; 12(7): 114551 .

[55] Bohannon RW, Brennan PJ, Pescatello LS, et al. Adiposity of elderly women and its relationship with self-reported and observed physical performance. J Geriatr Phys Ther 2005; 28(1): 10-3.

[56] Shumway-Cook A, Patla A, Stewart AL, et al. Assessing environmentally determined mobility disability: self-report versus observed community mobility. J Am Geriatr Soc 2005; 53(4): 7004.

[57] Guralnik JM, Fried LP, Salive ME. Disability as a public health outcome in the aging population. Annu Rev Public Health 1996; 17: $25-46$.

[58] Friedmann JM, Elasy T, Jensen GL. The relationship between body mass index and self-reported functional limitation among older adults: a gender difference. J Am Geriatr Soc 2001; 49(4): 398-403.

[59] Bjorntorp P. Evolution of the understanding of the role of exercise in obesity and its complications. Int J Obes Relat Metab Disord 1995; 19 (Suppl 4): S1-4.

[60] Svendsen OL, Hassager C, Christiansen C. Age- and menopauseassociated variations in body composition and fat distribution in healthy women as measured by dual-energy X-ray absorptiometry. Metabolism 1995; 44(3): 369-73.

[61] Spyropoulos P, Pisciotta JC, Pavlou KN, et al. Biomechanical gait analysis in obese men. Arch Phys Med Rehabil 1991; 72(13): 1065-70.

[62] NIH. Clinical Guidelines on the Identification, Evaluation, and Treatment of Overweight and Obesity in Adults--The Evidence Report. Obes Res 1998; 6(Suppl 2): 51S-209S.

[63] Consultation on Obesity. Obesity Preventing and managing the Global E. Consultation on Obesity. Obesity Preventing and managing the Global Epidemic. Geneva, Switzerland 2000.

[64] Bedogni G, Pietrobelli A, Heymsfield SB, et al. Is body mass index a measure of adiposity in elderly women? Obes Res 2001; 9(1): 1720.

[65] Blew RM, Sardinha LB, Milliken LA, et al. Assessing the validity of body mass index standards in early postmenopausal women. Obes Res 2002; 10(8): 799-808.

[66] Evans EM, Rowe DA, Racette SB, et al. Is the current BMI obesity classification appropriate for black and white postmenopausal women? Int J Obes (Lond) 2006; 30(5): 837-43. 
[67] Jankowski CM, Gozansky WS, Van Pelt RE, et al. Relative Contributions of adiposity and muscularity to physical function in community-dwelling older adults. Obesity (Silver Spring) 2008; 16(5): 1039-44.
[68] Lauretani F, Russo CR, Bandinelli S, et al. Age-associated changes in skeletal muscles and their effect on mobility: an operational diagnosis of sarcopenia. J Appl Physiol 2003; 95(5): 1851-60.

[69] Langlois JA, Keyl PM, Guralnik JM, et al. Characteristics of older pedestrians who have difficulty crossing the street. Am J Public Health 1997; 87(3): 393-7.

Received: October 13, 2008

Revised: November 20, 2008

Accepted: December 11, 2008

(C) Bouchard et al.; Licensee Bentham Open.

This is an open access article licensed under the terms of the Creative Commons Attribution Non-Commercial License (http://creativecommons.org/licenses/bync/3.0/), which permits unrestricted, non-commercial use, distribution and reproduction in any medium, provided the work is properly cited. 